\title{
First enantioselective synthesis of tetracyclic intermediates en route to madangamine D
}

\author{
Mercedes Amat,* Roberto Ballette, Stefano Proto, Maria Pérez, and Joan Bosch \\ Received (in $X X X, X X X)$ Xth $X X X X X X X X X 20 X X$, Accepted Xth XXXXXXXXX 20XX \\ DOI: 10.1039/b000000x
}

The enantioselective synthesis of advanced tetracyclic precursors of madangamine $D$, bearing rings $A B C D$ of this alkaloid, is reported. The saturated 14-membered ring is assembled from functionalized diazatricyclic intermediates ${ }_{10}$ following either ring-closing metathesis or macrolactamization strategies.

Madangamines are a small group of marine alkaloids isolated from sponges of the order Haplosclerida, biogenetically derived from oligomeric macrocycles bearing a partially reduced 3-

15 alkylpyridine moiety. Some of them possess significant in vitro cytotoxicity, ${ }^{2}$ although the low availability of samples has precluded further pharmacological studies. Their unique structure embodies a diazatricyclic core (ABC rings) unprecedented among natural products and two peripheral macrocyclic rings (Figure 1). 20 No total syntheses of madangamines have been reported to date, so the absolute configuration of these alkaloids remains unknown.

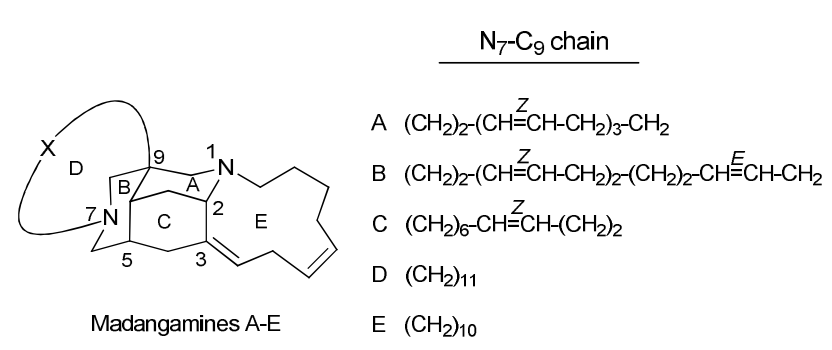

Fig. 1 Madangamine alkaloids.

We report herein the first enantioselective synthesis of advanced tetracyclic precursors of madangamine $\mathrm{D}$, bearing rings ABCD of this alkaloid. ${ }^{3}$ Starting from a phenylglycinol-derived oxazolopiperidone lactam, ${ }^{4}$ our approach involves the 30 enantioselective construction of the bridged diazatricyclic $\mathrm{ABC}$ ring system common to all madangamines, appropriately substituted and functionalized to allow the subsequent building of the macrocyclic $\mathrm{D}$ and $\mathrm{E}$ rings of these alkaloids (Scheme 1). In our strategy, the cis-fused carbocyclic $\mathrm{C}$ ring was installed in 35 early stages of the synthesis by stereoselective conjugate addition of an allyl residue, followed by a ring-closing metathesis reaction. Then, after stereoselective alkylation of the $\beta$-dicarbonyl moiety and reductive removal of the auxiliary oxazolidine ring, with simultaneous reduction of the lactam and ester groups, the
40 piperidine A ring was built up taking advantage of the alcohol and alkene functionalities in the resulting cisoctahydroisoquinoline derivative. Interestingly, the alkylation step allows a variety of functionalized chains to be stereoselectively incorporated on the quaternary C-9 stereocenter, 45 thus providing potential access to a variety of madangamines. The methoxycarbonyl group in the starting lactam 1 plays a triple role: it acts as an activating electron-withdrawing group in the conjugate addition reaction as well as in the subsequent alkylation, and is the precursor of the aminomethyl chain required ${ }_{50}$ for the closure of the piperidine A ring.
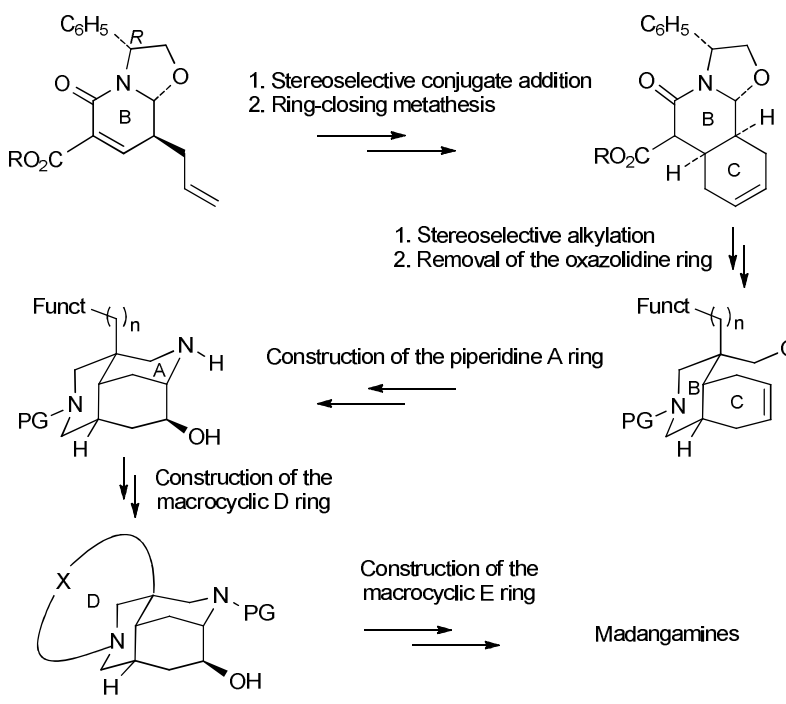

Construction of the piperidine A ring

1. Stereoselective alkylation 2. Removal of the oxazolidine ring

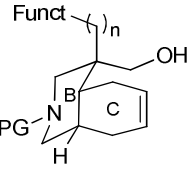
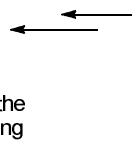

Construction of the macrocyclic E ring

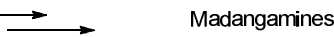

Scheme 1 Common synthetic strategy to madangamines.

55 Scheme 2 outlines the synthetic sequence leading to the functionalized azatricycle 7 . The cis-octahydroisoquinoline ring system was constructed in excellent yield from the unsaturated lactam $1,{ }^{5}$ by stereoselective conjugate addition of allylmagnesium bromide followed by ring-closing metathesis of 60 the resulting diene 2 (mixture of epimers at the $\mathrm{C}=\mathrm{O} \alpha$ position) using the second-generation Grubbs catalyst. Then, the crucial quaternary C-9 stereocenter of madangamines was generated with complete facial selectivity by alkylation of the epimeric mixture 3 with 2-(3-bromopropyl)-1,3-dioxolane, ${ }^{6}$ using $\mathrm{NaH}$ as the base, to ${ }_{65}$ give a single lactam 4 in $80 \%$ yield.

The reductive opening of the oxazolidine ring was 
accomplished by treatment of $\mathbf{4}$ with $\mathrm{Na}$ in liquid $\mathrm{NH}_{3}$, which caused the cleavage of the benzylic $\mathrm{C}-\mathrm{N}$ bond. A subsequent treatment with $\mathrm{LiAlH}_{4}$ brought about the reduction of the resulting unstable alkoxy(hydroxy) lactam as well as the lactam 5 and ester carbonyl groups to give an amino alcohol, which was converted without any purification to the $N$-Boc derivative $\mathbf{5}$.<smiles>C=CCC1C=C(C(C)=O)C(=O)N2C(P)COC12</smiles><smiles>C=CCC1C(=O)N2C(CCCCC)COC2C(CCCC)C1CC=C</smiles>

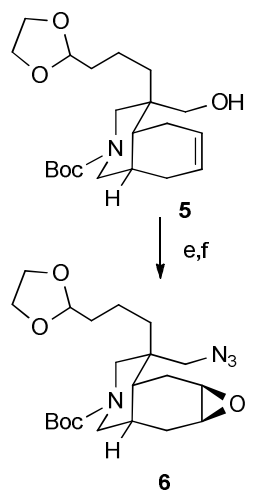
d
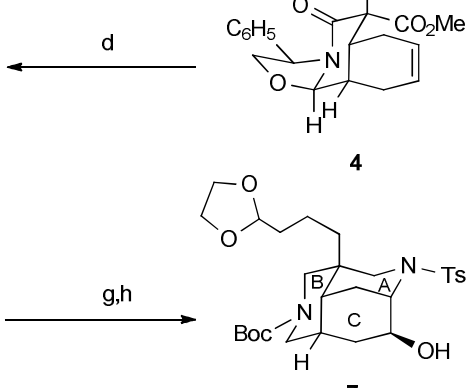

10 Scheme 2 Enantioselective construction of the azatricyclic ABC core of madangamines. Reagents and conditions: (a) $\mathrm{CH}_{2}=\mathrm{CHCH}_{2} \mathrm{MgBr}, \mathrm{CuI}$, LiCl, TMSCl, THF, $-78{ }^{\circ} \mathrm{C}, 20$ h, 81\%; (b) Grubbs 2nd gen., $\mathrm{CH}_{2} \mathrm{Cl}_{2}$, rt, 18 h, 85\%; (c) $\mathrm{NaH},\left(\mathrm{CH}_{2} \mathrm{O}\right)_{2} \mathrm{CH}\left(\mathrm{CH}_{2}\right)_{3} \mathrm{Br}$, TBAI, DMF, rt, 18 h, $80 \%$; (d) $\mathrm{Na}$ /liq. $\mathrm{NH}_{3},-33{ }^{\circ} \mathrm{C}, 2 \mathrm{~min}$; then $\mathrm{LiAlH}_{4}$, dioxane, reflux, $20 \mathrm{~h}$; then 15 (Boc) ${ }_{2} \mathrm{O}, \mathrm{CH}_{2} \mathrm{Cl}_{2}$, rt, 4 h, 42\%; (e) $\mathrm{Et}_{3} \mathrm{~N}, \mathrm{MsCl}, \mathrm{CH}_{2} \mathrm{Cl}_{2}, \mathrm{rt}, 4 \mathrm{~h}, 97 \%$; then $\mathrm{NaN}_{3}, \mathrm{DMF}, 90^{\circ} \mathrm{C}, 48 \mathrm{~h}, 70 \%$; (f) $m$-CPBA, $\mathrm{CH}_{2} \mathrm{Cl}_{2}, \mathrm{rt}, 5 \mathrm{~h}$; (g) $\mathrm{Me}_{3} \mathrm{P}$, THF, $1 \mathrm{~h}$; then $\mathrm{H}_{2} \mathrm{O}$, rt, $20 \mathrm{~h}$; (h) $p$-TsCl, $\mathrm{Et}_{3} \mathrm{~N}, \mathrm{CH}_{2} \mathrm{Cl}_{2}, 0{ }^{\circ} \mathrm{C}, 2.5 \mathrm{~h}, 40 \%$ (steps f-h).

20 After conversion of the hydroxy group into an azide via a mesylate and stereoselective $m$-CPBA epoxidation of the cyclohexene double bond, the closure of the piperidine A ring was performed by $\mathrm{Me}_{3} \mathrm{P}$ reduction of the intermediate azido epoxide 6. The initially formed amino epoxide underwent a 25 smooth in situ cyclization to give a tricyclic amino alcohol, which was immediately converted to the orthogonally protected diamino derivative 7. The above eleven-step synthetic sequence represents a notable improvement, in terms of simplicity, on the sixteen-step route previously developed ${ }^{7}$ for the preparation of related 30 diazatricyclic intermediates, for instance 8 (see Scheme 4). Notably, the method used for the removal of the phenylethanol moiety avoids redundant $\mathrm{N}$-protection/deprotection steps and unnecessary functional group manipulations, which lengthened our previous reported synthesis.

35 Compound 7, bearing a functionalized five-carbon chain at $\mathrm{C}$ 9, was envisaged as a suitable platform to construct the 14membered ring of madangamine $\mathrm{D}$ by ring-closing metathesis ${ }^{8}$ of an appropriate diene. Once the hydroxy group of 7 was protected by benzylation, orthogonal deprotection of the piperidine $\mathrm{B}$ ring 40 by treatment with TFA under anhydrous conditions, followed by

acylation with 7-octenoyl chloride, furnished the tricyclic amide 9, which was then converted to the diene $\mathbf{1 0}$ by deprotection of the acetal function followed by Wittig methylenation (Scheme 3). As expected, diene $\mathbf{1 0}$ satisfactorily underwent a ring-closing 45 metathesis reaction on treatment with the second-generation Grubbs catalyst under high-dilution conditions. ${ }^{9}$ Treatment of the resulting $Z / E$ mixture of alkenes with $\mathrm{H}_{2}$ and $\mathrm{PtO}_{2}$ brought about both the reduction of the carbon-carbon double bond and the hydrogenolysis of the benzyloxy group, leading to tetracyclic ${ }_{50}$ alcohol 11.
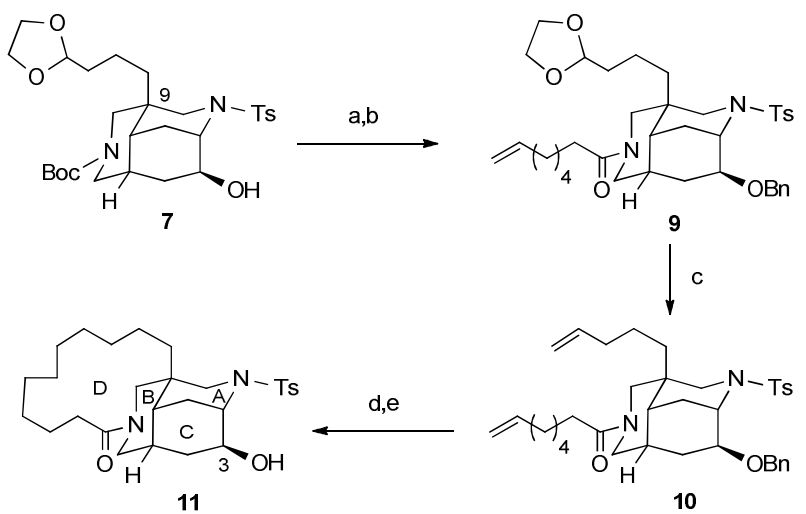

Scheme 3 Assembly of the 14-membered ring of madanamine D. The ${ }_{55} \mathrm{RCM}$ strategy. Reagents and conditions: (a) $\mathrm{NaH}, \mathrm{BnBr}, \mathrm{TBAI}, \mathrm{DMF}$, $0.05 \mathrm{M}, \quad \mathrm{rt}, 20 \mathrm{~h}, 80 \%$; (b) TFA, $\mathrm{CH}_{2} \mathrm{Cl}_{2}, \mathrm{rt}, 30 \mathrm{~min}$; then $\mathrm{ClCO}\left(\mathrm{CH}_{2}\right)_{5} \mathrm{CH}=\mathrm{CH}_{2}, \mathrm{Et}_{3} \mathrm{~N}, \mathrm{CH}_{2} \mathrm{Cl}_{2}, 0{ }^{\circ} \mathrm{C}, 3 \mathrm{~h}$; then rt, $18 \mathrm{~h}, 57 \%$; (c) TFA, $\mathrm{CH}_{2} \mathrm{Cl}_{2} / \mathrm{H}_{2} \mathrm{O}$, rt, $2 \mathrm{~h}$; then $\mathrm{KO}$ - $\mathrm{Bu}, \mathrm{Ph}_{3} \mathrm{PCH}_{3} \mathrm{Br}$, THF, rt, $20 \mathrm{~h}, 80 \%$; (d) Grubbs 2nd gen., $\mathrm{CH}_{2} \mathrm{Cl}_{2}, 0.2 \mathrm{mM}$, syringe pump, reflux, $12 \mathrm{~h}, 54 \%$; 60 (e) $\mathrm{H}_{2}, \mathrm{PtO}_{2}, \mathrm{MeOH}, \mathrm{rt}, 2 \mathrm{~h}, 78 \%$.

An alternative strategy for the assembly of the 14-membered ring of madangamine $\mathrm{D}$ is outlined in Scheme 4. Starting from diazatricyclic alcohol $\mathbf{8},{ }^{7}$ already incorporating the required 65 functionalized 11-carbon chain at C-9, conventional functional group interconversions led to acetal 12, and then to carboxylic acid 13. After removal of the protecting Boc substituent, macrolactamization of the crude amino acid under high-dilution conditions provided tetracyclic amide $\mathbf{1 4}$.
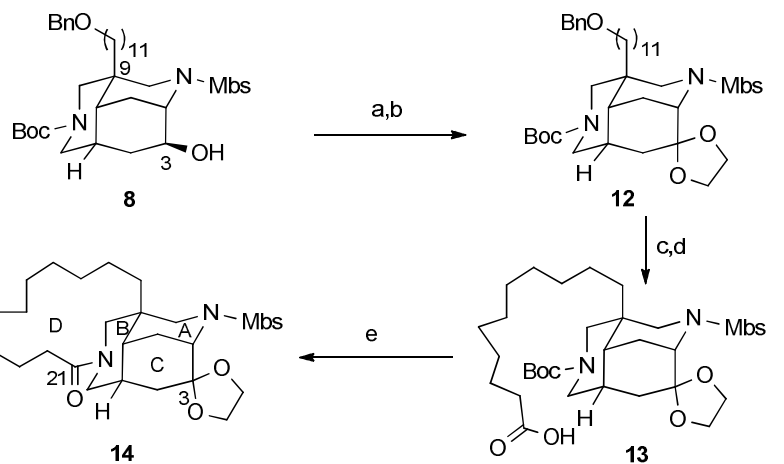

Scheme 4 Assembly of the 14-membered ring of madangamine D. The macrolactamization strategy. Reagents and conditions:(a) DMP, $\mathrm{CH}_{2} \mathrm{Cl}_{2}$, $75 \mathrm{rt}$, 4h, 1:1 saturated aqueous $\mathrm{NaHCO}_{3}-\mathrm{Na}_{2} \mathrm{~S}_{2} \mathrm{O}_{3}, \mathrm{rt}, 1 \mathrm{~h}, 78 \%$; (b) TMSOTf, $\left(\mathrm{CH}_{2} \mathrm{OTMS}\right)_{2}, \mathrm{CH}_{2} \mathrm{Cl}_{2}, 0{ }^{\circ} \mathrm{C}, 30 \mathrm{~min}$; then reflux, $1 \mathrm{~h}, 57 \%$; (c) 
$\mathrm{H}_{2}, \mathrm{Pd} / \mathrm{C}, \mathrm{MeOH}$, rt, 96 h, 73\%; (d) PDC, DMF, rt, 20 h, 63\%; (e) TFA, $\mathrm{CH}_{2} \mathrm{Cl}_{2}$, rt, $30 \mathrm{~min}$; then HOBt, EDCI, (9:1) DMF/ $\mathrm{CH}_{2} \mathrm{Cl}_{2}, 0.5 \mathrm{mM}, 0{ }^{\circ} \mathrm{C}$, $20 \mathrm{~h}, 43 \%$.

$5 \quad$ In summary, from diazatricyclic intermediates $\mathbf{7}$ and $\mathbf{8}$ we have developed two different strategies for the construction of the saturated 14-membered ring of madangamine $\mathrm{D}$, resulting in the first enantioselective synthesis of advanced tetracyclic precursors of this alkaloid.

10 Financial support from the Spanish Ministry of Economy and Competitiveness (Project CTQ2012-35250) and the AGAUR, Generalitat de Catalunya (Grant 2009-SGR-1111) is gratefully acknowledged. Thanks are also due to the Ministry of Education (Spain) for a fellowship to R.B.

\section{${ }_{15}$ Notes and references}

Laboratory of Organic Chemistry, Faculty of Pharmacy, and Institute of Biomedicine (IBUB), University of Barcelona, 08028-Barcelona, Spain. E-mail: amat@ub.edu; Fax:+34 9340245 39; Tel: +34 934024540

$\dagger$ Electronic Supplementary Information (ESI) available: Detailed 20 experimental procedures, copies of ${ }^{1} \mathrm{H}$ and ${ }^{13} \mathrm{C}$ NMR spectra for all compounds. See DOI: 10.1039/b000000x/

1 (a) F. Kong, R. J. Andersen and T. M. Allen, J. Am. Chem. Soc. 1994, 116, 6007; (b) F. Kong, E. I. Graziani and R. J. Andersen, J.

25 Nat. Prod. 1998, 61, 267; (c) J. H. H. L. De Oliveira, A. M. Nascimento, M. H. Kossuga, B. C. Cavalcanti, C. O. Pessoa, M. O. Moraes, M. L. Macedo, A. G. Ferreira, E. Hajdu, U. S. Pinheiro and R. G. S. Berlinck, J. Nat. Prod. 2007, 70, 538.

2 (a) R. J. Andersen, R. W. M. van Soest and F. Kong in Alkaloids:

30 Chemical and Biological Perspectives; ed. S. W. Pelletier, Pergamon, New York, 1996, vol. 10, pp. 301; (b) N. Matzanke, R. J. Gregg and S. M. Weinreb, Org. Prep. Proc. Int. 1998, 30, 1; (c) R. G. S. Berlinck, Top. Heterocycl. Chem. 2007, 10, 211.

3 For previous racemic syntheses of the diazatricyclic core of

35 madangamines, see: (a) N. Matzanke, R. J. Gregg, S. M. Weinreb and M. Parvez, J. Org. Chem. 1997, 62, 1920; (b) N. Yamazaki, T. Kusanagi and C. Kibayashi, Tetrahedron Lett. 2004, 45, 6509; (c) H. M. Tong, M.-T. Martin, A. Chiaroni, M. Bénéchie and C. Marazano, Org. Lett. 2005, 7, 2437; (d) J. Quirante, L. Paloma, F. Diaba, X.

40 Vila and J. Bonjoch, J. Org. Chem. 2008, 73, 768; (e) Y. Yoshimura, T. Kusanagi, C. Kibayashi, N. Yamazaki and S. Aoyagi, Heterocycles 2008, 75, 1329; (f) For a review, see: A. Nishida, T. Nagata and M. Nakagawa, Top. Heterocycl. Chem. 2006, 5, 255.

4 For reviews on the use of these chiral scaffolds in alkaloids synthesis,

45 see: (a) M. Amat, M. Pérez, J. Bosch, Synlett, 2011, 143; (b) M. Amat, M. Pérez and J. Bosch, Chem. Eur. J. 2011, 17, 7724; (c) M. Amat, N. Llor, R. Griera, M. Pérez and J. Bosch, Nat. Prod. Commun. 2011, 6, 515.

5 M. Amat, M. Pérez, A. T. Minaglia, N. Casamitjana and J. Bosch,

$50 \quad$ Org. Lett. 2005, 7, 3653.

6 This bromo acetal was prepared from ethyl 4-bromobutanoate by DIBAL reduction followed by acetalization of the resulting aldehyde: G. N. Varseev and M. E. Maier, Org. Lett. 2005, 7, 3881.

7 M. Amat, M. Pérez, S. Proto, T. Gatti and J. Bosch, Chem. Eur. J. 2010, 16, 9438 .

8 For model studies on the construction of D ring of madangamines, see: S. Proto, M. Amat, M. Pérez, R. Ballette, F. Romagnoli, A. Mancinelli and J. Bosch, Org. Lett. 2012, 14, 3916.

9 For reviews on the construction of macrocyclic rings by RCM

60 reactions, see: (a) Q. Meng and M. Hesse, Top. Curr. Chem. 1991, 161, 109; (b) A. Deiters and S. F. Martin, Chem. Rev. 2004, 104, 2199; (c) K. C. Nicolaou, P. G. Bulger and D. Sarlah, Angew. Chem. Int. Ed. 2005, 44, 4490; (d) A. Gradillas and J. Pérez-Castells, Angew. Chem. Int. Ed. 2006, 45, 6068. 